W 7 $\propto .5$ MUSEUM OF THE AMERICAN INDIAN HEYE FOUNDATION

Vol. VII, No. 5

\title{
A PERUVIAN QUIPU
}

BY

L. LELAND LOCKE 

CONTRIBUTIONS FROM THE

MUSEUM OF THE AMERICAN INDIAN

HEYE FOUNDATION

Vol. VII, No. 5

\section{A PERUVIAN QUIPU}

BY

L. LELAND LOCKE

NEW YORK

MUSEUM OF THE AMERICAN INDIAN

HEYE FOUNDATION

1927 



\section{A PERUVIAN QUIPU}

$\mathrm{BY}$

\section{LELAND LOCKE}

7 HE Inca civilization is unique in that it did not develop any system of writing, hieroglyphic, ideographic, phonetic, or alphabetic. With its highly organized governmental machinery, in which records of taxes, census, crops, and tributes were a necessary part, some device was necessary to preserve such numerical records. The quipu, or knot record, was a simple but exceedingly clever adaptation of the primitive and widely used method of tying knots on a string.

In the most perfectly developed form the quipu consists of a main strand to which are attached pendent strands, on each of which a number is arranged in decimal notation, with the units or ones at the lower end of the strand. The tens are tied above the ones, with the highest order appearing nearest the main or parent strand.

The successive orders thus lie in rows across the quipu, parallel to the main strand. The number in each order above the ones is usually a group of single knots, not exceeding nine, while the ones, or lowest order, is represented by what is termed the long knot, a loop with the strand passing through once for each one to be shown. A single one is generally represented by the single overhand or Flemish knot. A subsidiary strand was frequently attached to the pendent strand to note some disturbance in the count. When the items listed were in groups, it was customary to group the strands on the main strand, and frequently a top strand served to sum up the numbers in the group of pendent strands to which it was attached.

A conventional color scheme was in use, with certain colors for the different kinds of things to be recorded. With many of the preserved specimens it would seem that the colors were chosen according to the fancy of the maker. 
From recent studies ${ }^{1}$ the following conclusions may be drawn with respect to existing specimens which have been studied:

1. The quipu was used primarily for recording numbers.

2. The quipu was probably used as memoria technica in memorizing historical items, poems, lists of rulers, etc.

3. The quipu was not adapted to calculation.

4. The quipu was not a conventional scheme of writing.

In recent studies ${ }^{2}$ on the quipu, Baron Erland Nordenskiöld, in accounting for the practice of placing quipus in graves, has predicated as a theory that the grave quipus were calendrical in nature and may have been used for astrological or divination purposes. The frequent appearance of astronomical numbers in the published quipus gives considerable substantiation to this theory. In this study the numbers themselves are of paramount importance, and it is evident that if the true significance of the grave quipus is to be determined, it is essential that accurate readings of all complete or nearly complete quipus be rendered available for study. It is probable that a considerable body of astronomical knowledge will be shown to have been developed by the Incas.

There has recently come into the possession of the Museum of the American Indian, Heye Foundation, an exceedingly interesting specimen of the quipu, which is shown in the accompanying plate LXII. A schematic diagram of the knot readings and arrangement is also given (pl. LXIII). This specimen is practically perfect and is unique in several particulars.

The main strand is twisted of three strands, white, brown, and dark-brown. The dark-brown strand is badly disintegrated, due to the dye. This peculiarly dyed strand is found in many specimens.

\footnotetext{
${ }^{1}$ L. Leland Locke, The Ancient Quipu, A Peruvian Knot Record. American Anthropologist, 14, 2, April, 1912, 325-332.

L. Leland Locke, The Ancient Quipu or Peruvian Knot Record. American Museum of Natural History, 1923.

${ }^{2}$ Erland Nordenskiöld, The Secret of the Peruvian Quipus. Comparative Ethnographical Studies, no. 6, part 1, Oxford University Press, 1925.

Erland Nordenskiöld, Calculations with Years and Months in the Peruvian Quipus. No. 6, part 2, of above, 1925.
} 


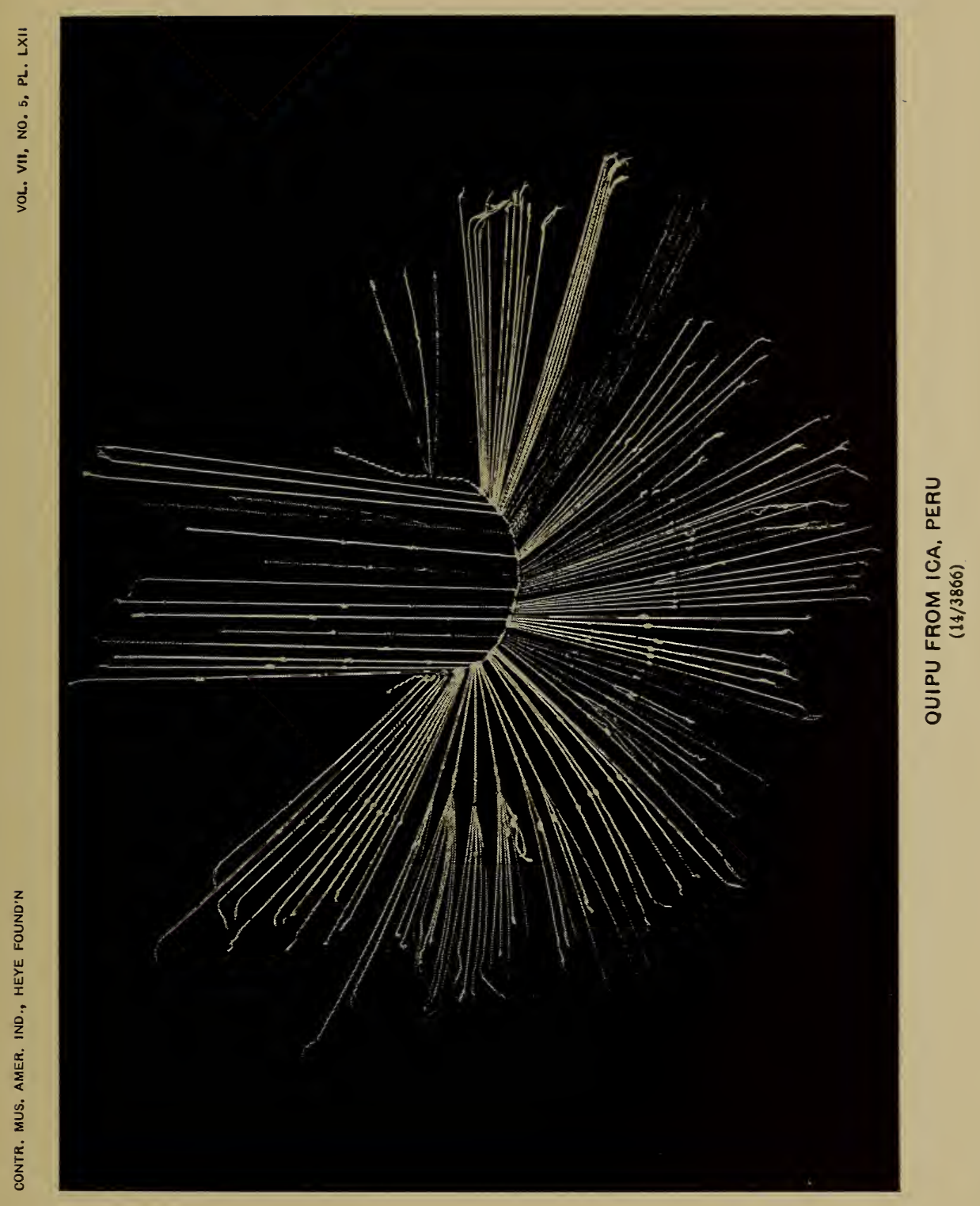



The quipu consists of fifteen groups of six pendent strands, each group of six having a top summing strand. At the end are three single strands.

In group $\mathrm{A}$, one thread of each strand is of dark-brown dye as in the main strand. These strands are partially loosed from the main strand, owing to the falling away of the brown thread. One strand is missing, but it is safe to assume the number on it from the summation strand at the top. Group B is complete, with the top strand summing the number on the pendent strands. Group $\mathrm{C}$ is to be noted on account of the number of subsidiary strands attached to strands 2 and 3 . There are seven attached to strand 2, only one of which contains a number. The six attached to strand 3 are not tied. This large number of subsidiary strands attached to a single strand is unusual, particularly so in that they have not been used. In group $\mathrm{J}$ the number on the top or summation strand is 43 , while the readings on the pendent strands total 45 . This may be due to a mistake on the part of the maker or again to an error in reading. In some cases, due to the character of the cord, certainty in the reading may be obtained only by untying the knot, which would not be desirable. In such cases the reading is verified and recorded as read. Beyond group $\mathrm{J}$ the groups contain no knots. Group $\mathrm{L}$ is very fragmentary, owing to the dye.

The three final cords, $\mathrm{P}, \mathrm{Q}$, and $\mathrm{R}$, are unusual, as they are not grouped and they contain numbers much in excess of the numbers on the grouped strands. Q is broken in the units knot, which has been at least one. The three strands have the appearance of a balance sheet or final summing up of the numbers on the grouped strands. This hypothesis fails if the quipu were supposed to be a record of items counted, since one would not know the total until the enumeration had been completed. The total on the top strands of the groups is 839 , with 71 on the subsidiary strands. The totals of $\mathrm{P}, \mathrm{Q}$, and $\mathrm{R}$ are at least 2795 .

The apparently unfinished condition of this quipu is easily explained if it had been used as a record of an enumeration, assuming the quipu to have been prepared in advance, just as one might select more sheets of paper than would be required for a particular 
piece of writing. A number of sheets would remain unused. This assumption permits of no easy solution of the last three strands.

If, as Nordenskiöld assumes, this is an astrological or astronomical quipu, where the maker builds up the numbers according to some principle or according to his fancy, it is easy to conjecture that he first set down the chosen numbers as totals on $P, Q$, and $R$, and proceeded to build up his combinations on the groups. An interruption in the work would account for the unfinished condition of the quipu. Another peculiarity of the specimen is that no subsidiary cords are attached to the summation strands at the top, except in group $\mathrm{K}$, which contains no subsidiary strands on the pendent cords and does have one attached to the summation strand. No knots have been tied in this group. In other specimens examined the subsidiary strands attached to the summation strands sum up the subsidiary strands of the group of pendent strands. 






\section{NOTES}

Conventions: $F$ indicates a Flemish knot, $S$ a single knot, and $L$ a long knot. Asterisks indicate the positions of subsidiary strands.

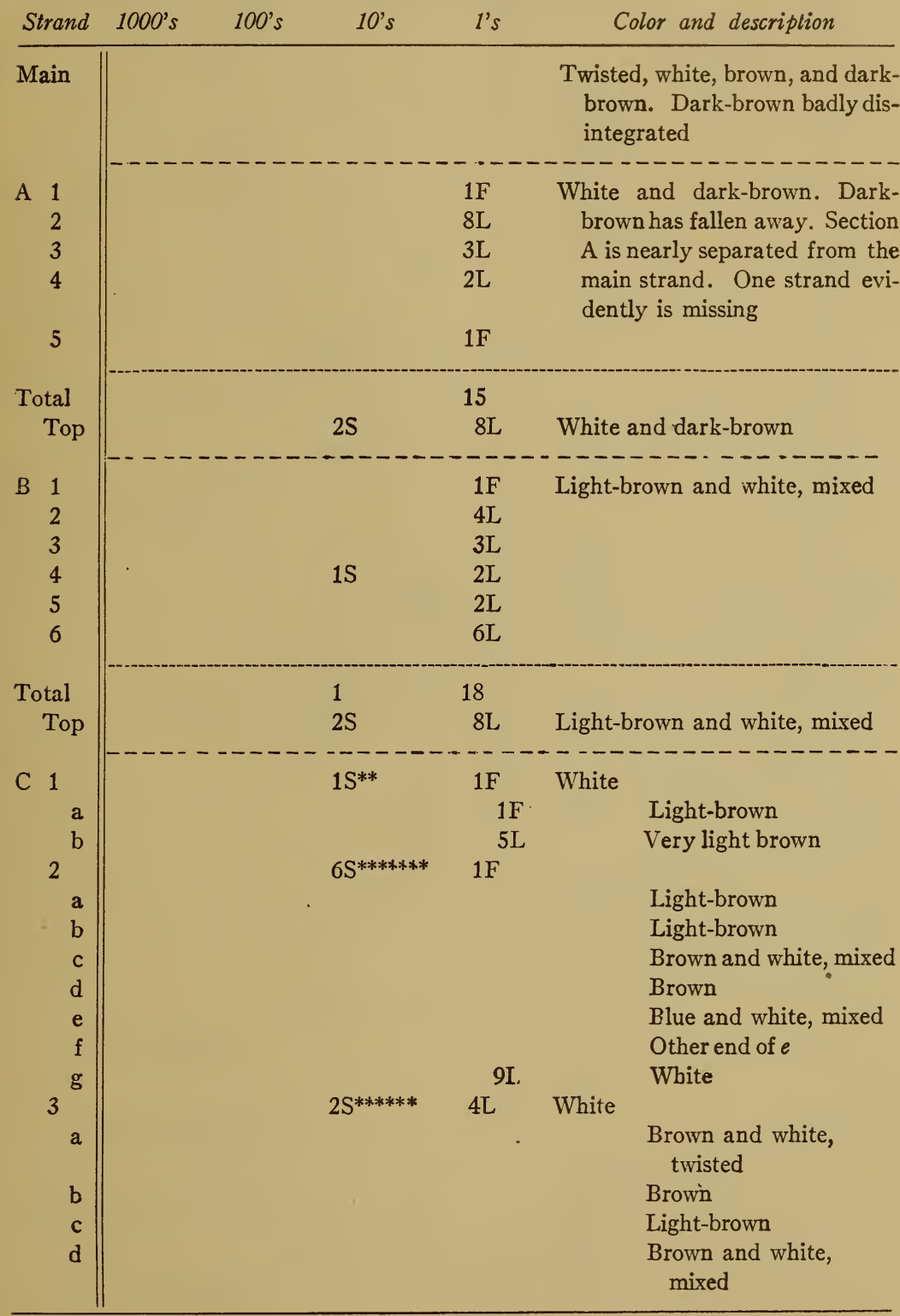




\begin{tabular}{|c|c|c|c|c|c|c|}
\hline & & & NOTES- & -Continn & & \\
\hline Strand & 1000 's & 100 's & 10 's & l's & & olor and description \\
\hline e & & & & & & White \\
\hline f & & & & & & $\begin{array}{l}\text { Blue and white, } \\
\text { mixed }\end{array}$ \\
\hline 4 & & & $9 S^{* * * * * * *}$ & 9L & White & \\
\hline a & & & & & & Light-brown \\
\hline b & & & & & & Brown \\
\hline c & & & & & & $\begin{array}{l}\text { Brown and white, } \\
\text { mixed }\end{array}$ \\
\hline d & & & & 9L & & White \\
\hline & & & & $3 \mathrm{~L}$ & & Brown \\
\hline f & & & & $7 \mathrm{~L}$ & & Blue and white, mixed \\
\hline $\mathrm{g}$ & & & & & & Brown \\
\hline 5 & & & $1 \mathrm{~S} * *$ & $9 \mathrm{~L}$ & White & \\
\hline a & & & & & & Light-brown \\
\hline b & & & & & & Brown \\
\hline 6 & & & $1 \mathrm{~S} * *$ & 9L & White & \\
\hline a & & & & & & Brown \\
\hline & & & & & & $\begin{array}{l}\text { Brown and white, } \\
\text { mixed }\end{array}$ \\
\hline Total & & & 20 & 3334 & & \\
\hline Top & $2 \mathrm{~S}$ & & $3 \mathrm{~S}$ & $3 \mathrm{~L}$ & White & \\
\hline D 1 & & & & $4 \mathrm{~L}$ & White & \\
\hline 2 & & & 1S & $3 \mathrm{~L}$ & $\begin{array}{r}\text { Tips, br } \\
\text { twist }\end{array}$ & $\begin{array}{l}\text { own and white, } \\
\text { d }\end{array}$ \\
\hline 3 & & & & $5 \mathrm{~L}$ & & \\
\hline 4 & & & $2 \mathrm{~S}$ & $3 \mathrm{~L}$ & & \\
\hline 5 & & & & $5 \mathrm{~L}$ & & \\
\hline 6 & & & & $1 \mathrm{~F}$ & & \\
\hline Total & & & 3 & 21 & & • \\
\hline Top & & & $5 \mathrm{~S}$ & $1 \mathrm{~F}$ & Same a & \\
\hline E 1 & & & * & $7 \mathrm{~L}$ & Brown & \\
\hline a & & & & 4L. & & $\begin{array}{l}\text { White and brown, } \\
\text { twisted }\end{array}$ \\
\hline 2 & & & $4 S^{* * *}$ & & & \\
\hline a & & & 1S & & & $\begin{array}{l}\text { White and brown, } \\
\text { twisted }\end{array}$ \\
\hline $\mathrm{b}$ & & & & $3 \mathrm{~L}$ & & Blue \\
\hline c & & & & $2 \mathrm{~L}$ & & Blue and white, mixed \\
\hline 3 & & & $2 \mathrm{~S} *$ & $1 \mathrm{~F}$ & Brown & \\
\hline a & & & & $1 \mathrm{~F}$ & & $\begin{array}{l}\text { Brown and white, } \\
\text { mixed }\end{array}$ \\
\hline
\end{tabular}




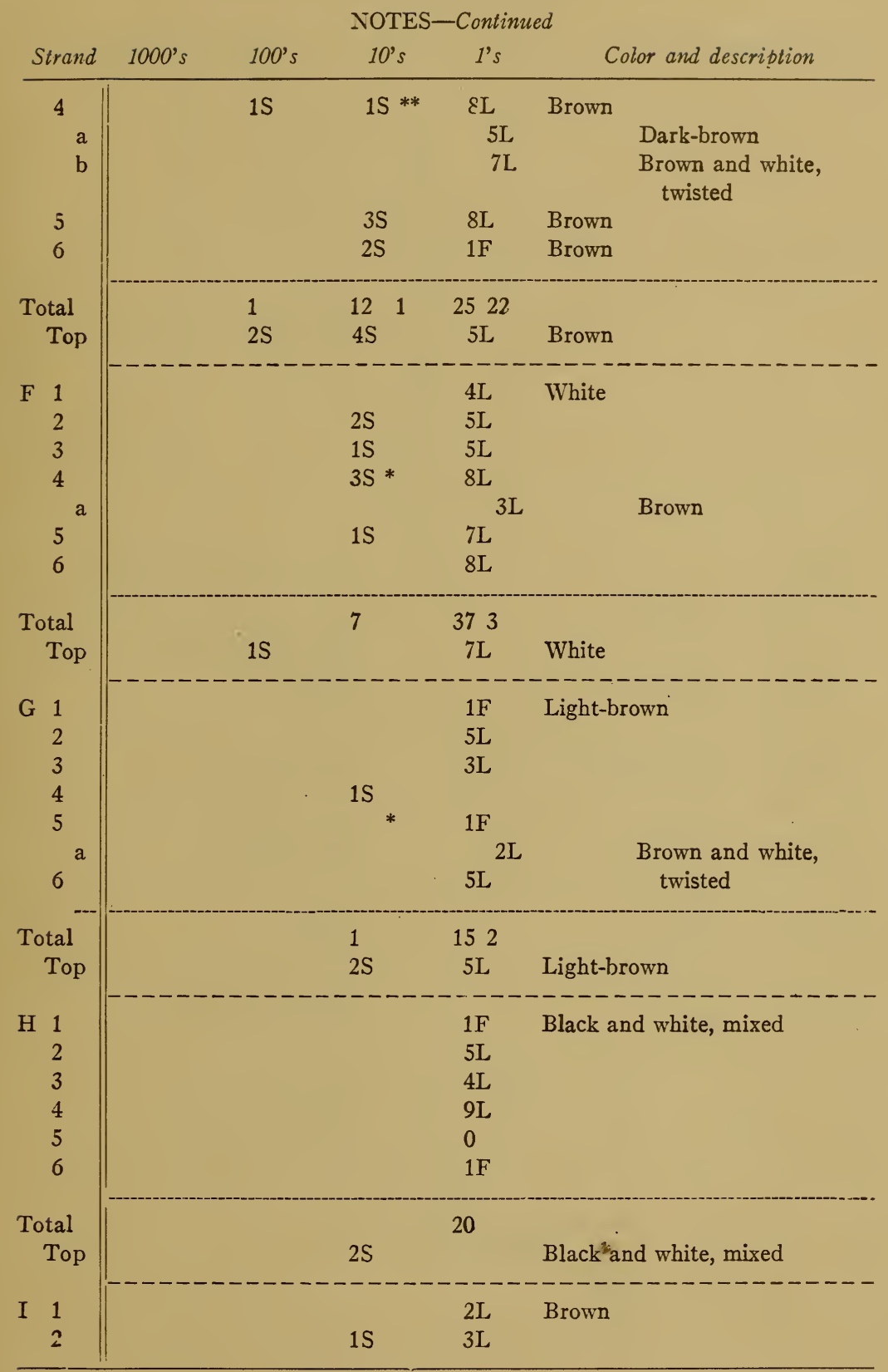




\begin{tabular}{|c|c|c|c|c|c|c|}
\hline \multirow[b]{2}{*}{ Strand } & \multicolumn{6}{|c|}{ NOTES-Continued } \\
\hline & 1000 's & & 100 's & 10 's & l's & Color and description \\
\hline 3 & & & & & $3 \mathrm{~L}$ & \\
\hline 4 & & & & $2 \mathrm{~S}$ & 9L & \\
\hline 5 & & & & & 9L & \\
\hline 6 & & & & & $3 \mathrm{~L}$ & \\
\hline Total & & & & 3 & 29 & \multirow[b]{2}{*}{ Brown } \\
\hline Top & & & & $5 S$ & 9L & \\
\hline J 1 & & & & & $4 \mathrm{~L}$ & \multirow[t]{6}{*}{ Brown and white, mixed } \\
\hline 2 & & & & 1S & $2 \mathrm{~L}$ & \\
\hline 3 & & & & & $4 \mathrm{~L}$ & \\
\hline 4 & & & & $1 \mathrm{~S}$ & $8 \mathrm{~L}$ & \\
\hline 5 & & & & & $4 \mathrm{~L}$ & \\
\hline 6 & & & & & $3 \mathrm{~L}$ & \\
\hline Total & & & & 2 & 25 & \multirow[b]{2}{*}{ Brown and white, mixed } \\
\hline Top & & & & 4 & $3 \mathrm{~L}$ & \\
\hline K 1-6 & \multicolumn{3}{|c|}{ No knots } & & & $\begin{array}{l}\text { Top, brown and white, twist } \\
\text { Remainder, white }\end{array}$ \\
\hline \multirow{2}{*}{$\begin{array}{r}\text { Top } \\
\text { a }\end{array}$} & \multirow{2}{*}{\multicolumn{3}{|c|}{ No knots }} & & & \multirow{2}{*}{$\begin{array}{l}\text { Same as K 1-6 } \\
\text { White }\end{array}$} \\
\hline & & & & & & \\
\hline L $1-6$ & \multicolumn{3}{|c|}{ Fragmentary } & & & Dark-brown \\
\hline \multirow{2}{*}{$\begin{array}{r}\text { M } 1-6 \\
\text { Top }\end{array}$} & \multicolumn{3}{|c|}{ No knots } & & & \multirow{2}{*}{$\begin{array}{l}\text { Light-brown and white } \\
\text { Same as M 1-6 }\end{array}$} \\
\hline & & $\mathrm{kn}$ & ots & & & \\
\hline \multirow{2}{*}{$\begin{array}{r}\text { N } 1-6 \\
\text { Top }\end{array}$} & \multicolumn{3}{|c|}{ No knots } & & & White \\
\hline & \multicolumn{3}{|c|}{ No knots } & & & White \\
\hline \multirow{2}{*}{$\begin{array}{r}\text { O } 1-6 \\
\text { Top }\end{array}$} & \multicolumn{3}{|c|}{ No knots } & & & \multirow{2}{*}{$\begin{array}{l}\text { Blue and white, mixed } \\
\text { Same as } 01-6\end{array}$} \\
\hline & & $\mathrm{kn}$ & ots & & & \\
\hline $\mathrm{P}$ & & & $2 S$ & $4 \mathrm{~S}$ & $5 \mathrm{~L}$ & Dark-brown \\
\hline Q & 1S & & $3 \mathrm{~S}$ & 9S & ? & Gray, fragmentary \\
\hline \multirow[t]{2}{*}{$\mathrm{R}$} & $1 \mathrm{~S}$ & & 1S & $5 \mathrm{~S}$ & 9L & Dark-brown \\
\hline & \multicolumn{6}{|c|}{ SUMDIARY } \\
\hline A & 28 & & Whit & darl & own & \\
\hline B & 28 & & Whit & ligh & own & \\
\hline C & 233 & 34 & Whit & & & \\
\hline D & 51 & & Whit & & & \\
\hline
\end{tabular}


NOTES-Concluded

\begin{tabular}{l||rrl}
\hline E & 245 & 32 & Brown \\
$\mathrm{F}$ & 107 & 3 & Brown \\
$\mathrm{G}$ & 25 & 2 & Light-brown \\
$\mathrm{H}$ & 20 & & White and black \\
$\mathrm{I}$ & 59 & & Brown \\
$\mathrm{J}$ & 43 & & Brown and white \\
Total & 839 & 71 & \\
$\mathrm{P}$ & 245 & & Dark-brown \\
$\mathrm{Q}$ & 1391 & ? & Gray \\
$\mathrm{R}$ & 1159 & & Dark-brown \\
Total & 2795 & & \\
\hline
\end{tabular}






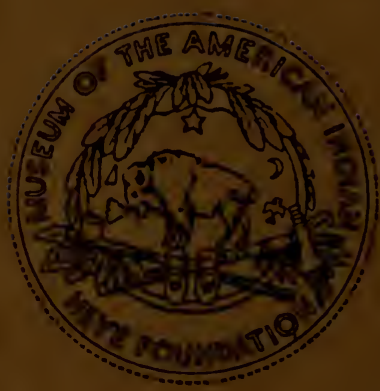

